\title{
Experiencing authenticity - the core of student learning in clinical practice
}

\author{
Katri Manninen ${ }^{1}$
}

Published online: 15 September 2016

(C) The Author(s) 2016. This article is available at SpringerLink with Open Access.

\begin{abstract}
Introduction Learning in clinical practice is challenging regarding organizational and pedagogical issues. Clinical education wards are one way to meet these challenges by focusing on both patient care and student learning. However, more knowledge is needed about how students' learning can be enhanced and about patients' and supervisors' roles in these settings.

Methods The aim was to explore nursing students' learning on a clinical education ward with an explicit pedagogical framework. Semi-structured interviews of students were analyzed using qualitative content analysis and an ethnographic study including observations and follow-up interviews of students, patients and supervisors was conducted. Results The core of student meaningful learning experiences both external and internal authenticity. Students in early stages immediately created mutual relationships, experienced both external and internal authenticity, and patients became active participants in student learning. Without a mutual relationship, patients passively let students practice on their bodies. Students nearing graduation experienced only external authenticity, creating uncertainty as a threshold for learning. Caring for patients with complex needs helped students overcome the threshold and experience internal authenticity. Supervisors' challenges were to balance patient care and student learning by working as a team. They supported students coping with the complex challenges on the ward.
\end{abstract}

Katri Manninen

katri.manninen@ki.se

1 Karolinska Institutet, Department of Learning, Informatics, Management and Ethics, Stockholm, Sweden
Discussion/Conclusion Students need to experience external and internal authenticity to make learning meaningful. Experiencing authenticity, involving meaning-making processes and knowledge construction, is linked to transformative learning and overcoming thresholds. Therefore, an explicit pedagogical framework, based on patient-centredness, peer learning and the supervisory team, creates the prerequisites for experiencing external and internal authenticity.

Keywords Clinical practice $\cdot$ Learning $\cdot$ Pedagogical framework · Authenticity

\section{Introduction}

In clinical settings the main focus is to provide patient care; education has a secondary role. This has been shown to jeopardize the possibilities for students to learn [1, 2]. Although the need for students to practise in clinical settings is acknowledged, this secondary role may result in insufficient organizational resources and the neglect of students' educational support. Instead of helping students connect theoretical and practical knowledge and skills in patient-centred care, the risk is that supervisors focus on completing workload and controlling students [1]. Students also express loneliness and lack of support in their learning [2]. Most patients have a positive attitude regarding involvement in students' learning, but sometimes they feel excluded from the communication between students and supervisors [3]. Clinical education wards have been established to enhance the integration of theory and practice, professional development and collaboration between clinical and educational settings. These wards train students at different levels and 
focus on inter-professional training or on one profession [4, 5].

The context for this thesis is a clinical education ward for nursing students at a university hospital in Sweden. The ward has eight beds and trains students at different levels. Fifteen students do their clinical practice simultaneously during a six-week placement. Five supervisors work on the ward, four are nurses and one is an assistant nurse. A physician and a senior clinical lecturer also serve as supervisors. A physiotherapist, dietician, occupational therapist and counsellor are linked to the ward. Patients are mainly admitted from the emergency department. The ward has a pedagogical framework based on an interpretation of Mezirow's [6] theory of transformative learning. It consists of three parts: patient-centred learning, supervisors' support and peer learning. Students are allowed to act as nurses; they work both individually and together with peers with support from the supervisors.

The focus of this research project was to explore and understand students' learning in this specific context from multiple perspectives.

\section{Methods}

Four studies were conducted, all with qualitative approaches based on constructivist and interpretative tradition [7], to explore nursing students' learning in relation to encounters with patients, supervisors, peer students and other healthcare professionals. Data collection methods that were used were interviews and observations including field and reflective notes. The qualitative approaches allow an exploration of the phenomenon in its natural settings which means that the participants construct meanings of their experiences in interaction with other people, the researcher included. The researcher then makes an interpretation of the meanings resulting in co-constructed knowledge. Qualitative content analysis and ethnographic approach were used in the analysis.

In the first and second studies students' experiences of their learning were explored using semi-structured individual and group interviews. The focus was on exploring how students experience their encounters with 1) patients, 2) supervisors, 3) peer students and 4) other healthcare professionals. Participants were asked to discuss and reflect on the encounters and the interviewer asked follow-up, probing and explanatory questions to obtain both broad and indepth data. In the first study 19 first-year students were interviewed, and in the second study 18 final-year students were interviewed. Data from both studies were analyzed using qualitative content analysis focusing on the underlying meanings, i.e. the latent content of the data [8]. The findings from these two studies resulted in a need to explore interactions between students, patients and supervisors. Therefore in studies three and four an ethnographic approach [9] was used. Participant observations with follow-up interviews of 11 students, 10 patients and 5 supervisors, and a group interview of the supervisors were conducted. Study three focused on exploring patient-student encounters and in study four the focus was on exploring the pedagogical role of supervisors. During the observations extensive field notes including both observational and reflective notes were taken. Observational notes included description of activities and interactions, while reflective notes consisted of the observer's thoughts and questions when observing. After each observation an individual follow-up interview was conducted. The participants were asked to talk about what had happened during the observation and how they felt about it. In the group interview of the supervisors they were asked to talk about their experiences and thoughts about supervision. Data from the observations were analyzed following an ethnographic approach which involves description, analysis and interpretation. This means describing and examining the relationships and linkages between the data from both observations and interviews and making an interpretation beyond the description [9].

\section{Results}

The results show that the core of student meaningful learning is the experience of both external and internal authenticity. External authenticity refers to being in a real clinical setting meeting real patients. Internal authenticity is about the feeling of belonging and really contributing to patients' health and well-being. The theory of transformative learning and the concepts of authenticity and threshold [6, 10, 11] were used to interpret the findings.

1. Students in the early stages of their education immediately created mutual relationships with patients and experienced both external and internal authenticity [12]. These mutual relationships became a basis for students' learning. They also experienced belongingness which means a feeling of being a real part of the professional team taking care of patients. Students showed a patientcentred approach when learning.

2. For students nearing graduation, the learning process turned out to be more complex [13]. Students started out by expressing self-centredness and ambivalence in their relationships with patients, supervisors and peer students, which created uncertainty as a threshold for their learning. This resulted in experiencing only external authenticity. When the students took care of patients with extensive needs for nursing interventions they man- 
aged to overcome this threshold. They then experienced engagement consisting of creating mutual relationships and professional development, meaning that they also experienced internal authenticity.

3. Patients were always positively engaged in students learning but they were involved either actively or passively [14]. If the student created a good atmosphere and mutual relationships, the patient became an active participant in a joint action resulting in a learning relationship between them. If the student only created a one-way relationship, the patient became a passive participant resulting in an attending relationship. Oneway relationships were characterized by students and patients communicating past each other. The patient became a training object; just lending a part of the body for the student to train on.

4. Supervisors' approaches to and pedagogical role in students' learning involved balancing patient care and student learning by being simultaneously patient- and student-centred [15]. This created a pedagogical challenge which they handled by working as a team and allowing students independence with support. Furthermore they made care plans for the patients and learning plans for the students following the clinical and pedagogical guidelines.

\section{Discussion}

The findings show that authenticity has two dimensions, external and internal. Furthermore, experiencing authenticity is needed for meaningful and transformative learning. When students experience both external and internal authenticity, they make sense of their experiences and their learning becomes meaningful. These experiences involve challenges and need support to result in a process of meaning-making and knowledge construction. This process is also linked to transformative learning by Mezirow [6] and the findings of Land et al. [11] regarding learning in the liminal space, meaning that transformative learning involves overcoming thresholds. On a clinical education ward, characterized as the setting explored, transformative learning involves experiencing both external and internal authenticity, which forms the basis for creating learning relationships between patients and students. However, experiencing authenticity and mutual relationships is potentially troublesome and there are thresholds to overcome, particularly for students nearing graduation [6, 11]. Thus, supervisors need to acknowledge students' different learning processes. The pedagogical framework is intended to help students overcome the thresholds, but accomplishing this depends on whether they understand and make use of the potential for learning. Students' ability to think reflectively and to tolerate uncertainty is implied in the pedagogical framework. The supervisors' role in the liminal space is crucial, as they provide both challenges and support. They identify students' needs and help them through the transformative learning process by acknowledging the liminal space and troublesome knowledge [11]. Accordingly, supervisors need to have contextual knowledge, which is knowledge in different sciences tied to the context, which constitutes the pedagogical content knowledge needed to enhance student learning in clinical settings.

\section{Conclusion}

The core of student learning in clinical practice is the experience of both internal and external authenticity. An explicit pedagogical framework based on patient-centredness, peer learning and the supervisory team creates prerequisites for experiencing authenticity.

\section{One piece of advice}

To succeed with your thesis, have both short- and longterm goals with a step-by-step-plan to achieve them. Think SMART when you choose your goals as they should be specific, meaningful, accurate, realistic and time-bound. Discuss with your supervisors and peers and do not underestimate the power of reflection!

Acknowledgements This thesis was completed within Karolinska Institutet, Stockholm, Sweden and defended on 23 May 2014. My transformative learning process would not have been possible without a team of supervisors: Charlotte Silén, Elisabeth Welin Henriksson and Max Scheja.

Funding This research was supported by grants from the Regional Agreement on Medical Training and Clinical Research (ALF) between the Stockholm County Council and Karolinska Institutet.

Open Access This article is distributed under the terms of the Creative Commons Attribution 4.0 International License (http:// creativecommons.org/licenses/by/4.0/), which permits unrestricted use, distribution, and reproduction in any medium, provided you give appropriate credit to the original author(s) and the source, provide a link to the Creative Commons license, and indicate if changes were made.

\section{References}

1. Sedgwick M, Harris SA. Critique of the undergraduate nursing preceptorship model. Nurs Res Pract. 2012;2012:248356.

2. Rydlo C. Fighting for the otherness - Student nurses' lived experiences of growing in caring. Doctoral Thesis. Örebro Studies in Care Sciences. Örebro University, 2010. 
3. Monrouxe LV, Rees CE, Bradley P. The construction of patients' involvement in hospital bedside teaching encounters. Qual Health Res. 2009;19:918-30.

4. Brewer ML, Stewart-Wynne EG. An Australian hospital-based student training ward delivering safe, client-centred care while developing students' interprofessional practice capabilities. J Interprof Care. 2013;27:482-8.

5. Moscato SR, Nishioka VM, Coe MT. Dedicated education unit: implementing an innovation in replication sites. J Nurs Educ. 2013;52:259-67.

6. Mezirow J. An overview on transformative learning. In: Illeris K, editor. Contemporary theories of learning. Learning theorists ... in their own words. London: Routledge; 2009. pp. 90-105.

7. Savin-Baden M, Howell Major C. Qualitative research. The essential guide to theory and practice. London: Routledge; 2013.

8. Graneheim UH, Lundman B. Qualitative content analysis in nursing research: concepts, procedures and measures to achieve trustworthiness. Nurse Educ Today. 2004;24:105-12.

9. Hammersley M, Atkinson P. Ethnography. Principles in practice, 3rd ed. London: Routledge; 2007.

10. McCune V. Final year biosciences students' willingness to engage: teaching-learning environments, authentic learning experiences and identities. Stud High Educ. 2009;34:347-61.
11. Land R, Rattray J, Vivian P. Learning in the liminal space: a semiotic approach to threshold concepts. High Educ. 2014;67:199-217.

12. Manninen K, Welin Henriksson E, Scheja M, Silén C. Authenticity in learning - nursing students' experiences at a clinical education ward. Health Educ. 2013;113:132-43.

13. Manninen K, Scheja M, Welin Henriksson E, Silén C. Self-centeredness or patient-centeredness-final year nursing students' experiences of learning at a clinical education ward. J Nurs Educ Pract. 2013;3:187-98.

14. Manninen K, Welin Henriksson E, Scheja M, Silén C. Patients' approaches to students' learning at clinical education ward-an ethnographic study. BMC Med Educ. 2014;14:131.

15. Manninen K, Welin Henriksson E, Scheja M, Silén C. Supervisors' pedagogical role at a clinical education ward - an ethnographic study. BMC Nurs. 2015;14:55.

Katri Manninen, RN, MSc, PhD, is currently working as senior clinical lecturer and researcher at Karolinska University Hospital, Department of Infectious Diseases, Red Cross University College and Karolinska Institutet, Stockholm, Sweden. 